PART 3

CONTINUITY AND DISCONTINUITY AROUND THE JOB MARKET 
Andrea Galimberti and Eva Ratti - 9789004375475 Downloaded from Brill.come4/26/2023 09:43:55AM via free access 


\title{
7. CONTINUITY AND DISCONTINUITY AROUND ACADEMIA
}

\author{
The "Find Your Doctor" Project as a Space for \\ Researching and Facilitating Learning Careers
}

\section{"WE DON'T KNOW HOW TO DO ANYTHING ELSE": A PERSONAL EXPERIENCE}

In the summer of 2012, an Italian astrophysics graduate who is one of the authors of this article was completing her $\mathrm{PhD}$ in the Netherlands, and wondering what it was about her career situation that was making her unhappy. While sharing her doubts and thoughts with peers, she found herself listening to the personal career stories of other PhD candidates, post-docs and young researchers: gathering de facto a small but vibrant sample of experiences, impressions and viewpoints concerning career paths in research and related issues.

Although neither premeditated nor systematically conducted, these initial dialogues nonetheless offered valuable material for reflection. First, they suggested widespread insecurity about future employment possibilities and stability in public research, which the reader may recognise as a common concern for young academics across different disciplines and (Western) countries (Fumasoli et al., 2015). The second point of interest was that, despite their justified perception that there was little scope for them to develop a life-long career in science, the majority of these young researchers were not actively seeking out alternatives. On the contrary, they mostly intended to continue along the "post-doc-after-post-doc" path they anticipated for themselves, hoping that if they could withstand the pressure and, in some cases, homesickness for their native land, if they could deal with family issues, if they were good enough and strong enough, etcetera, some - as yet unforeseeable - solution would eventually turn up.

For a few of them, this choice was driven by a deep-set passion for research: they intended to go on doing and enjoying their dream job for as long as they possibly could. The majority, however, did not have such a strong sense that research was their one true calling: they did not dislike it, they appreciated its advantages, but were also acutely aware of its drawbacks. While the first group refused to imagine themselves "doing something else", the second group was more open to this possibility, but could not pinpoint a plausible "else". The overall conviction of this group of young academics was (and has since remained) that most of them would stay on in 
indefinitely in research because they could not identify a realistic alternative given what they knew - or thought they knew - about the world outside the academy.

"If I could turn back, I don't know if I would still choose this life" one young post-doc commented during an impromptu conversation at the front door of the research institute: "But I am fairly good at it and, let's face it, we don't know how to do anything else".

\section{INSIDE/OUTSIDE OF THE ACADEMY: WHAT'S ON THE HORIZON FOR PHDS?}

Surprisingly, in light of the growing interest in career prospects for $\mathrm{PhDs}$ displayed by many academic institutions, we were unable to find systematically collected international statistics on the percentages of annual $\mathrm{PhD}$ graduates that are expected to eventually achieve a permanent position in higher education. Although the situation can be depicted as tragic or not-so-tragic depending on the country and field of knowledge considered, it is reasonable to estimate that a $\mathrm{PhD}$ graduate's current chance of ultimately attaining a permanent position in public research is a few per cent on average, and may be even slimmer in certain geographical contexts.

For example, the 2013 European Science Foundation Report on research careers in Europe cites a study, based on annual reports filed by Finnish universities, indicating that roughly $10 \%$ of newly-qualified $\mathrm{PhDs}$ can expect to attain a professorship. In Italy, the situation is even worse: a recent study carried out by ADI - the national association of $\mathrm{PhD}$ students and $\mathrm{PhD}$ graduates - predicts that only $6.5 \%$ of current Post-doc researchers will obtain long-term academic positions (ADI, 2016). Van der Weijden and colleagues have outlined a similar situation in Dutch universities (Van der Weijden et al., 2015). The MORE 2 Higher Education Survey (2012) reported a decrease in long-term academic positions in favour of temporary contracts, in both the US and EU27, for those who had embarked on PhD programmes after 2006 as compared to those who had initiated their doctoral studies earlier.

The first decade of the 2000s saw a major increase in the number of $\mathrm{PhDs}$ granted globally each year, but this was not matched by an equivalent increase in permanent academic positions (OECD, 2011). Although the pattern may have changed over the last few years, for which international data have not yet been reported, it is reasonable to assume that this growth produced a large reservoir of professionals with research experience. Career data from the OECD Research and Development Statistics Database that included information on short-term contract employment, showed that in 2011, the business sector in the OECD area absorbed - on average - some $45 \%$ of researchers (OECD, 2011). If we also take into account non-researchers, that is to say, $\mathrm{PhD}$ holders who are currently not employed in research, the percentage employed by enterprise is likely to be even higher, particularly in the humanities in which fewer research positions are available compared to engineering and the hard sciences (Auriol, Misu, \& Freeman, 2013).

There is also data to suggest that the broader jobs market is open to receiving $\mathrm{PhD}$ graduates, given that unemployment rates for the category remain below national 
averages and below equivalent rates for Master's degree holders (OECD, 2016). The European-level DOC-CAREERS project found that half of current PhDs hold research and non-research positions in the business, government, services and nonthird-level education sectors (EUA, 2009, p. 7). So, why do PhD holders fail to identify future career options for themselves outside of academia? In our opinion, one of the reasons may be the lack of a suitable intermediary assisting $\mathrm{PhD}$ graduates (especially those moving to non-research positions) to make the transition to new professional settings. Doctoral graduates' typically poor awareness of the range of career paths available to them has been repeatedly been flagged as a crucial stumbling block in studies on the topic, as clearly stated by the European Science Foundation's (ESF) forum on research careers: "Information on research career perspectives", says the 2012 ESF report: "has focused on the academic career because systematic information is not readily available for the different career alternatives in other fields". And again: "the post-doctoral period is a critical stage for selecting a research career as a profession, but information about further research career prospects is not readily available in a structured way" (ESF, 2012, p. 5).

\section{UNIVERSITY AND SOCIETY. THE TIMES THEY'RE A 'CHANGIN'?}

The fact that $\mathrm{PhD}$ graduates are relatively uninformed about career possibilities outside the academy calls into question the role of universities in the so-called "knowledge economy" (Livingstone \& Guile, 2012).

Over time, the academic world has modified its relationship with society by adapting its functions or missions (Scott, 2006). The two traditional tasks of universities, teaching and research, date back to the pre-modern era, prior to the birth of nation states. Today, the new activities demanded of higher education institutions by the knowledge society are referred to as their "third task" or "third stream" of activity, and imply changes in how universities are organised and design their curricula. Specifically, higher-education curricula are meant to provide for continuing professional development, thereby contributing to lifelong learning.

In this "age of supercomplexity" (Barnett, 2000), educational systems are continuously required to engage with new questions and new ideas about their relationship with knowledge. In the future, higher education's commitment to pursuing predominantly "formal" knowledge will increasingly be challenged, given the current politically- and market-led tendency to value the informal and nonformal dimensions of learning (Collini, 2012). Personal knowledge and transversal skills are becoming ever more important and this focus on competences implies the need for a different approach to teaching:

The concept of competence involves two critical questions for formal education. First, how important and relevant is its academic content in relation to societal reproduction and diffusion of knowledge and skills? Second, how 
effective are student-learning outcomes? Can people actually use in practice the knowledge and skills they have learned? (Olesen, 2013, p. 156)

These questions become salient as academic learning processes are increasingly drawn into dialogue with similar processes unfolding in non-university settings.

In the early stages of launching the European Research Area, a European Commission Communication noted that research is increasingly conducted in 'non-academic' institutions, such as companies, non-profit organizations and independent research centers and that researchers need to be trained and prepared to enter this wider job market. (EC, 2003, p. 14)

Enhancing the employability of university graduates (including $\mathrm{PhD}$ holders) will involve leveraging the developing relations between academic institutions and their new interlocutors. The changes underway entail new opportunities and new risks. One of the main risks derives from the idea that all universities need to do is adapt to market requirements. This assumption often underpins attempts to eliminate the distance between the academic sphere and the private sector via a sort of 'marketization' process (Collini, 2012). On the other hand, there is also the possibility that enriching new dialogues may take place. Attaining this second outcome is more challenging because it requires universities to pursue their academic mission in collaboration with other contexts and stakeholders, while maintaining their own distinct goals, interests and logics.

A key example of an "unconventional" interlocutor for universities is the world of small and medium enterprises. At both the formal and informal levels, the possible professional outlet for $\mathrm{PhD}$ graduates that is almost never mentioned is precisely the small and medium businesses sector, although it accounts for the greater part of European entrepreneurship. Small and medium companies are extensively present across all nations and potentially offer a broad range of working conditions, approaches and environments that may be matched with the individual values and needs of employees. Encouraging these companies to recruit researchers could significantly boost the choice of geographical locations and employment settings available to $\mathrm{PhD}$ holders. However, smaller businesses are more challenging interlocutors than large ones given their even greater cultural distance from the world of research, which has traditionally remained separate from the applied challenges of the market, business and production. Although (at least in Italy) a number of public and private initiatives aimed at facilitating contact between universities and companies have flourished in recent years, attempts to create links with small and medium businesses specifically, have met with little success to date. And this despite the fact that SMEs stand to benefit enormously from such a partnership. Broadly speaking, the main reason for this difficulty is the marked intrinsic difference between the goals, logics, timeframes and language of academia and those of small and medium-sized companies. However, if we shift from a model of organisationto-organisation interaction to one of personal contact, the scope for convergence 
increases. An individual researcher's motivation to find a suitable career path can truly be paired with a company's specific needs for expertise, a spirit of innovation and solutions.

\section{LOST IN TRANSLATION. THE FIND YOUR DOCTOR PROJECT}

In an increasingly knowledge-based society, where innovation is depicted as a key goal for companies and the complexity and rapid diffusion of information makes the ability to organise and synthesise knowledge so crucial (Livingstone \& Guile, 2012), it seems particularly wasteful that the very people who are trained in these skills remain stuck in an unnecessary contest for the few academic tenure positions available. On the other hand, there is a genuine risk that dialogue with the private sector will be perceived as frustrating if the distinctive characteristics of academic research experience fail to be recognised, integrated, and valued:

Over-qualification and over-skilling lead to lower levels of productivity, lower job satisfaction and psychological stress, besides being on aggregate level a waste in terms of investment made in education. (Flisi et al., 2014, p. 11)

The ESF 2012 report emphasised the need for communication initiatives connecting universities and the private sector:

As universities cannot be expected to provide jobs for a majority of researchers, funding programmes to support career opportunities in RPOs, industry and administration should be actively advertised. (ESF, 2012, p. 32)

Alongside the sustained, albeit debatably efforts of institutions and universities across Europe to enhance the employability of $\mathrm{PhDs}$, we believe that initiatives involving both the academic and entrepreneurial worlds could make career options in industry more visible, and researchers' professional experiences more accessible. Such an initiative is the FindYourDoctor project, launched by an Italian consortium of private companies and operated by a team of professionals from both academic and business backgrounds. The aim of the project - which is run on a no-profit basis - is to provide a reference point for junior and less-junior PhD holders in all fields and of all nationalities, facilitating their contact with the entrepreneurial world, making their value accessible to broader society and challenging the idea that "researchers do not know how to do anything else".

In practice, FyD is based around a website (www.findyourdoc.org), which collates professional profiles of $\mathrm{PhDs}$ on the one hand and profiles of companies interested in recruiting researchers on the other. Indeed, the web - alongside informal networks is increasingly being recommended to researchers as a resource for promoting their competences:

Individual scientists may provide examples of their personal careers and different web portals are available. In interviews, doctoral researchers 
themselves have reported positive experiences from their own network (of peers) for mentoring, coaching and career planning. (ESF, 2012, p. 5)

In our experience also, informal networks, advice from peers, and word-of-mouth via the web seem to be the most effective forms of support currently available to $\mathrm{PhD}$ graduates leaving higher education. The first-hand experience of the FindYourDoctor staff and careful analysis of web spaces, groups and forums on the topic suggest that the main online job-search portals and off-line job-placement agencies often provide little help, as they generally do not handle such high-level qualifications and niche areas of specialisation. Smaller initiatives exist in some countries: some are forprofit enterprises and related to particularly strategic market areas (e.g., big data analysis and strategic consultancy), while others are publicly funded, such as the interesting DocPro in France (www.mydocpro.org) which offers the most advanced discussion on the competences of $\mathrm{PhD}$ graduates that we have found to date.

Most current job-search instruments are largely based on keywords: online portals automatically filter applications for specific terms that conventionally do not feature in academic CVs, although the candidate may well possess the skills they denote. Similarly, the first level of the recruitment process via agencies is usually based on a list of schematic minimum requirements that are summarised in keywords, making it difficult for researchers' profiles to reach the desks of those who truly understand the requirements of the job to be filled and might be able to read between the lines of the PhD holder's experience.

We recently monitored an online discussion among researchers who were advising a recent $\mathrm{PhD}$ graduate in biology on the best way to write her $\mathrm{CV}$ to target a job in industry. Among many more or less reasonable suggestions, one in particular reflected a common misconception: "Keep it simple and let your research speak for itself". While this would be appropriate advice if one were applying for an academic position, in an initial screening process for a managerial position such as the case in hand, "letting the research speak for itself" would most likely come across to the recruiter as gibberish. Even when a researcher's CV is brought to the attention of someone with an in-depth understanding of the job requirements, as can happen in small companies with no structured recruitment offices, the highly specific expertise offered by a researcher may seem too much and too little at the same time. Vice versa, the requirements articulated in job-advertisements make many PhDs feel unfit because they feel that they cannot claim the expected labels.

Hence, job-search and job-placement procedures for researchers can be as effective as throwing two people that speak different languages into a room together and asking them to identify their common interests. In other words, the process cannot work, unless we introduce a translator.

\section{TRANSLATION AND TRANSFERABLE SKILLS}

Careful consideration of research training from an enterprise-oriented perspective reveals that many of the skills implicitly developed through research practices 
are required in a variety of positions of responsibility across a range of work environments (EUA, 2009). In the course of a good PhD programme, the student is trained to define, manage, and complete a multi-year project, locate the resources and expertise required to achieve each of the project goals, work on cross-national teams both as a coordinator and a team player, provide and accept feedback, and communicate and disseminate results in written and oral presentation format. We expect $\mathrm{PhD}$ graduates to be familiar with the methods of research, but in fact they have also learned to be proactive, driven and focused; and have received indepth training in analytical thinking and problem solving, intellectual consistency, accuracy, deep and creative thinking, and an awareness of the novel, given that they have been working to push forward the frontiers of knowledge. All skills that are not easily found and that companies of different sizes seek and value in candidates for analytical positions and roles of responsibility. In a survey conducted in the UK, $60 \%$ of $\mathrm{PhD}$ graduates reported using the generic skills developed as research students in their everyday work (Vitae, 2010, pp. 34-37). However, unless a company's staff includes doctorate holders that are involved in the recruitment process, none of this will necessarily be extrapolated from a standard academic CV.

Research experience can be difficult for a potential employer to interpret, just as it is difficult for researchers themselves to discern what aspect of their experience may be of interest outside of their former work setting and on what grounds. Assessment processes may fail to shed light because the concept of competence itself has not been clearly enough defined. In fact:

The term competence is sufficiently vague to be used by people in very different ways according to their particular assumptions and agendas. (Illeris, 2009, p. 8)

Multiple attempts have been made to define the key competences for knowledgebased economies (e.g., the European ESCO project). The outcomes are lists of abstract and "universal" skills. Particular emphasis is placed on so-called "soft", "transversal", "cross sector" or "transferable" skills, which are considered to be workers' best resource in an increasingly competitive economy based on "grey capital" (Field, 2006).

Cross-sector skills and competences can be transferred from one occupation to another, thus enabling occupational mobility. They can be used in a number of similar occupations and sectors but might require additional training to be used in a new job and/or work environment. Cross-sector skills and competences are of growing importance all over Europe. (ESF, 2009, p. 47)

It is frequently claimed that workers in all sectors require competences that go beyond their own specific field and need to acquire transferable skills throughout their careers to enhance their professional prospects (EUA, 2010). Researchers are no exception to this rule: 
Researchers today face new academic pathways and expanded opportunities to work in other sectors, as well as pressure to consider a wider variety of career paths and to use a wider variety of skills in their everyday work. To meet these challenges, researchers need skills that will allow them to work in and move between different sectors during their working lives and to cope with networked, interdisciplinary modes of work. (OECD, 2012, p. 16)

Increasing attention is being paid to the question of how researchers are trained in transferable skills: do they acquire such skills in the course of their studies? The EUA has suggested that researchers need to be more aware of the implicit acquisition of skills that takes place during their $\mathrm{PhD}$ programme and better able to convey it to potential employers (EUA, 2009, p. 93).

This kind of reflection often prompts attempts to devise formal and systematic training models with the explicit aim of creating suitable contexts for the teaching of transferable skills. Such models are intended to foster the development of transferable competences by leveraging the "informal" and tacit dimensions of learning processes. The results, to date, have generally been disappointing. Vitae (2009) found relatively high percentages of researchers who had undergone training in some area of personal and transferable skills but had not found it useful. Such unsatisfactory outcomes are likely related to the fact that the nature of transferable skills (as well as the concept of competence, see above) is problematic. Before analysing the best way to acquire them, it is crucial to examine the assumptions underlying the discourse on competences.

In general, the dominant discourse frames competences as commodifiable human abilities (Han, 2009), describing them as measurable and manageable. Some scholars see the notion of competence as fully embedded in the economic discourse (Olsen, Codd, \& O'Neill, 2004). In fact the concept of competence as a 'tradable good' is based on a notion of invariance that is difficult to reconcile with concepts of situated performance or of knowledge as interwoven with practice and historical context:

The interest of political management in being able to measure and compare across countries requires a common and general descriptive system. Efforts have therefore been directed towards defining key competencies. The concept of competence contains a contradiction between that defined above and a notion of invariance. (Olesen, 2013, p. 156)

This is not the only flaw in the mainstream definition of skills and competencies as mere "things" to be exchanged in the marketplace:

If we view competences as mere 'things', we fail to see the processes they activate. We fail to reflect on how it may be possible to elicit competent behaviour. We fail to identify the dynamic processes implicated in developing, sustaining and modifying competences. (Cepollaro, 2008, p. 78)

The use of an instrumental metaphor (Lakoff \& Johnson, 1980) to conceptualize competence has the drawback of obscuring its situated and relational nature: that 
is to say, the fact that competences are developed in specific settings, in the course of interaction, and through participation in complex professional activities. This consideration has a range of epistemological implications, concerning, for example, the role of tacit knowledge in acquiring situational understanding (Eraut, 2000) or whether practical knowledge that is embedded in specific activities and relations may be transferred to a different context. Relying on the instrumental definition can induce us to overlook the fact that transferring competences is not the same thing as transferring goods:

Labour, it seems, is a remarkably 'sticky' factor of production. Many skills do not transfer easily from one setting to another, presumably because they are often embedded in dense networks of workplace relationships. (Field, 2006, p. 102)

Interpretive approaches invite us to consider worker and work as forming "one entity through the lived experience of work. Competence is thus seen as constituted by the meaning the work takes on for the worker in his or her experience of it" (Sandberg, 2000, p. 11). Complexity theories (Morin, 1995) describe competences as the result of contingent, provisional and contextual processes, as an emerging organisation dealing with order/disorder. From this perspective, it is of crucial importance to link our knowledge of a given element to our knowledge of the whole it belongs to; and to uphold the principle of distinction, rather than disjunction, between the object, or subject, and their environment.

These theoretical points of view introduce an alternative frame of reference that emphasises relational and contextual aspects. A change in frame of reference often raises new issues and new questions (Mezirow, 2009). The key question is no longer: "How can we acquire general and abstract skills that are transferable?", but: "What kind of transformation occurs when we move from one context to another?", and: "What kind of learning processes are activated by this move?"

Gregory Bateson proposed that information gleaned from relating different contexts to one another bears learning potential (see the concept of "deuterolearning" in Bateson, 1972). Moving to a different professional setting may be an opportunity to identify and revisit the roots (contexts, relationships, tacit learning) of one's own skills, and to uncover the frames of reference and assumptions that shaped the related learning processes.

The current project was designed and implemented based on these theoretical considerations.

\section{THE STATE OF THE ART. WHAT DOES THE PROJECT INVOLVE?}

\section{A Successful Translation Initiative. Researchers Are Not Aliens after All}

In the course of 2015 and 2016, we had the opportunity to test some of the ideas outlined above in collaboration with an association of small and medium enterprises that is interested in helping its members to innovate. We set out to verify whether the 
needs of these smaller companies and the skills offered by PhDs could be matched in practice, and whether it was possible for the two parties to work together successfully when an "interpreter" was provided.

In this case, given that we were operating locally, the translator was a physical person: Eva Ratti, the FyD project manager, whose academic background complemented her colleagues' corporate experience. We set up trials with twelve companies, mediating short-term consultancy services focused on solving highly specific problems. Such short-term consultancy arrangements, potentially leading to longer-term collaboration, turned out to be of extreme interest to small enterprises and an excellent opportunity to demonstrate that researchers can be a valuable resource when it comes to analysing and solving real-life, practical problems. Thirtysix young researchers were recruited from all over Italy to take part in the project: all were post-docs or PhD graduates in different branches of physics, engineering, and materials science. Our "translator" was present at all meetings with the participating companies, and also acted as coordinator of the teams that we put together ad hoc to work on the individual company projects. At the end of each trial, we asked for feedback from the company and the team of PhDs, obtaining an extremely positive response from both parties. As a result, a permanent cooperation agreement has been established between Find Your Doctor and the industrial association that facilitated the test phase.

"They [the researchers] are not aliens after all" commented the production manager of one of the companies we worked with, to peers potentially interested in trying out the consultancy service: "Once you really get down to discussing the issue, we do speak the same language".

"We expected that only somebody senior would be able to tackle a complex problem like ours" said another: "On the contrary, the [researchers] who came to us were young, but they asked the right questions, they listened to us and were very helpful".

Furthermore, the contribution of the FyD mediator was represented as crucial. "She got them to speak to one another" was the comment.

Such positive feedback lent support to our idea that the expertise offered by researchers can be of value to small businesses too, and we believe that this will also prove to be true in other contexts, such as local government institutions, organisations and associations who might benefit from drawing on the expertise of $\mathrm{PhD}$ graduates in the humanities and social sciences to address issues of social innovation. The organisations in question "only" need to become aware of $\mathrm{PhDs}$ as a resource.

\section{Narratives and the Web. Beyond Standard CVs: The Potential Offered by a Narrative Approach}

Although the basic structure of our website is very similar to existing job-search portals, with companies and researchers both registering and browsing through each other's profiles and adverts, FyD differs from the standard in many ways. 
First and foremost, we direct our efforts towards devising the most effective possible presentation of the PhDs' profiles and customising the search engine used by the companies to browse through them.

Here, in fact, the translation problem described in the previous paragraphs manifests itself in force: how is it possible to narrow down one's search to a single entry in a database of hundreds? Keywords are required, but which are the most appropriate?

Of course, nothing can replace an interview, which is an indispensable part of any selection process. Indeed, our aim is to obtain interview opportunities for the $\mathrm{PhDs}$, despite the apparent discrepancy between the experience outlined in their CVs and the needs of the average employer. This entails shifting the focus from labelling the candidate's experience to unpacking the actions required to produce it, and the attitudes and modes of thinking underpinning successful completion of the actions.

We may take a stock sentence from research resumes as an example: "I have published several papers in major peer-reviewed journals" is a meaningful statement when applying for an academic position but likely meaningless in most other contexts. "I am able to write accurate reports in English, work cooperatively with others - including remotely, and mediate among different points of view; in addition, I have learned to take and give feedback constructively" presents the same experience in an entirely different light.

Another key factor in determining the suitability of a given person for a certain role or context is his/her set of values. "I have worked as tutor and lecturer in university courses" is understandable per se, but still not particularly meaningful to prospective employers unless they know what teaching implies or happen to be looking for a trainer. "I liked teaching because I value the sharing of knowledge and enjoy contact with people" tells a far more interesting story.

Of course, we could directly teach researchers how best to write their CVs and indeed we are currently working towards offering such training via our network. Meanwhile, however, we have designed the website in such a way as to elicit a first step in the right direction, by guiding our subscribers through the creation of their profiles.

More specifically, we have devised sets of questions that invite researchers to reflect on their professional experience to date by getting them to focus on areas that frequently involve transversal skills (see Blomeke et al., 2013) such as creativity and innovation, rigour, managing risk and uncertainty, communication and networking. We have chosen to offer jobseekers a narrative space rather than measuring their competences via online tests (despite the growing popularity of the latter approach). Candidates' responses are fully viewable on their FyD profiles, making for better communication with potential employers. We next plan to analyse these narrative texts with a view to identifying categories for mapping researchers' learning experience. This might be viewed as reversing the typical paradigm whereby those seeking employment are asked to describe their professional selves by choosing among a predefined set of categories, whose meaning may be unclear or perceived 
as not readily applicable to certain kinds of experience. In contrast, because those registering on the FyD website are invited to freely answer open questions, their accounts of their work experience may be organised into categories, creating a language that we ourselves will have defined and is therefore unambiguous to us. We plan to build this set of categories a-posteriori, following the methods of "constructivist" Grounded Theory (Charmaz, 2006) and working with computer scientists who are currently developing an experimental tool that will use the categories to construct an individualised multidimensional professional profile for each subscriber.

\section{CONCLUSIONS}

FindYourDoctor is, first and foremost, an attempt to support and promote researchers outside the boundaries of academia, and so to address a critical issue for the contemporary labour market:

In the last two to three decades, socio-economic changes such as increasing global competition, the skill-biased technological change or the ageing of population have resulted in a labour market situation where it is difficult to find the right people for the right jobs. Skill mismatch has become a major concern as it proves to be pervasive, widespread and persistent in developed economies resulting on real costs on individuals, businesses and society as a whole. (Flisi et al., 2014, p. 78)

While extending the employment options available to $\mathrm{PhDs}$ is one of our aims, we do not view FyD as a mere 'talent fishing' agency for companies. We also intend it to offer a space of self-reflection and learning for all those on research career paths who may have doubts about continuing, for motivational, personal, practical, philosophical or any other reasons. A place to reflect on one's strengths and options, reviewing past experience in the context of a broader range of future possibilities, so that the admirable and challenging decision to pursue an academic career may be consciously made and not adopted by default as a highly costly Plan B. An opportunity that may contribute to "unsticking" professional careers (Field \& Lynch, 2015) perceived as blocked or interrupted. To further this objective we organise seminars both inside and outside the university setting, with the collaboration of $\mathrm{PhD}$ schools (currently at the universities of Milan and Turin) and $\mathrm{PhD}$ associations.

The project is also designed to become a research space in which the different learning career paths undertaken by participants will help us to explore professional transitions (Fenwick, 2013) between academic and other work contexts. In particular, we are interested in unpacking the transferable skills that can facilitate the transition process. As a variety of scholars have noted, competency is a "floating signifier", indicating nothing more than "whatever employers want" (Lafer, 2004, p. 118). This critique will inform an in-depth investigation of the experience and expectations of 
both researchers and private companies, aimed at uncovering the variety of specific meanings and practical scenarios associated with the notion of transferable skills.

Finally, we are aware that all labour market issues are embedded in politics and power relations (Sawchuck, 2008). Many authors have warned about the risk of new institutional forms of control via the colonisation of informal learning (Hager \& Hallyday, 2008) and new forms of governmentality (Andersson \& Fejes, 2005; Fejes \& Dahlsted, 2013). For example, the risk of being excluded from the job market encourages forms of self-discipline whereby subjects are willing to expose private aspects of themselves in the hopes that this will increase their perceived value (Fejes \& Dahlsted, 2013). In light of this danger, we deliberately invite researchers to explore and present their professional practices and learning processes while avoiding an undue focus on the 'self', an approach that is often associated with testing. In any case, ethical considerations such as these constantly inform our work and decisions concerning the key boundaries that we need to enforce in order to protect the integrity and private sphere of our interlocutors.

\section{REFERENCES}

ADI. (2016). VI Indagine Adi su dottorato e Post-Doc. Retrieved from https://dottorato.it/sites/default/ files/survey/vi-indagine-adi-postdoc.pdf

Andersson, P., \& Fejes, A. (2005). Recognition of prior learning as a technique for fabricating the adult learner: A genealogical analysis on Swedish adult education policy. Journal of Education Policy, 20, 595-613.

Auriol, L., Misu, M., \& Freeman, R. A. (2013). Careers of doctorate holders: Analysis of labour market and mobility indicators (OECD Science, Technology and Industry Working Papers, 2013/04). Paris: OECD Publishing.

Barnett, R. (2000). Realising the university in an age of supercomplexity. Buckingam: Open University Press.

Batzson, G. (1972). Steps to an ecology of mind. New York, NY: Ballantine Books.

Blomeke, S., Zlatkin-Troitschanskaia, O., Kuhn, C., \& Fege, J. (Eds.). (2013). Modelling and measuring competencies in higher education. Tasks and challenges. Rotterdam, The Netherlands: Sense Publishers.

Brown, P., Green, A., \& Lauder, H. (2001). High skills: Globalisation, competitiveness and skill formation. Oxford: Oxford University Press.

Boreham, N. (2004). A theory of collective competence: Challenging the neo-liberal individualisation of performance at work. British Journal of Educational Studies, 52(1), 5-17.

Borrell-Damian, L. (2009). Collaborative doctoral education: University-industry partnerships for enhancing knowledge exchange. Brussels: EUA.

CEDEFOP. (2010). The skill matching challenge: Analysing skill mismatch and policy implications. Luxembourg: Publications Office of the European Union.

Charmaz, K. (2006). Constructing grounded theory: A practical guide through qualitative analysis. London: Sage Publications.

Coffield, F. (2000). Introduction: A critical analysis of the concept of learning society. In F. Coffield (Ed.), Different visions of learning society. Bristol: Policy Press.

Cepollaro, G. (2008). Le competenze non sono cose. Lavoro apprendimento, gestione dei collaboratori. Milano: Guerini.

Collini, S. (2012). What are universities for? London: Penguin Books.

Eraut, M. (2000). Non-formal learning and tacit knowledge in professional work. British Journal of educational Psychology, 70, 113-136. 
EC (European Commission). (2003). Researchers in the European research area: One profession, multiple careers, communication from the commission to the council and the European parliament. Retrieved from http://eur-lex.europa.eu/legal-content/en/ALL/?uri=CELEX:52003DC0436

ESF (European Science Foundation). (2009). Research careers in Europe: Landscapes and horizons: A report by the ESF member organisation forum on research careers. Strasbourg: ESF.

ESF (European Science Foundation). (2012). Developing research careers in and beyond Europe: enabling - observing - guiding and going global: A report by the ESF member organisation forum 'European alliance on research career development. Strasbourg: ESF.

ESF (European Science Foundation). (2013). Research careers in Europe. Landscapes and horizons. A report by the ESF member organisation forum on research careers. Strasbourg: ESF.

Fejes, A., \& Dahlstedt, M. (2013). The confessing society: Foucault, confession and practices of lifelong learning. Abingdon: Routledge.

Fenwick, T. (2013). Understanding transitions in professional practice and learning: Towards new questions for research. Journal of Workplace Learning, 25(6), 352-367.

Field, J., \& Lynch, H. (2015). Getting stuck, becoming unstuck: Agency, identity and transition between learning contexts. Journal of Adult and Continuing Education, 21, 3-17.

Flisi, S., Goglio, V., Meroni, E., Caetano Rodrigues, J., Rodrigues Ferro, M., \& Vera Toscano, E. (2014). Occupational mismatch in Europe: Understanding overeducation and overskilling for policy making. Brussels: Publications Office of the European Union.

Fumasoli, T., Goastellec, G., \& Kehm, B. M. (2015). Academic work and careers in Europe, trends, challenges, perspectives. Dordrecht: Springer.

Gergen, K. (1999). An invitation to social construction. London: Sage Publications.

Hager, P., \& Hallyday, J. (2008). Recovering informal learning: Wisdom, judgment and community (Lifelong Learning Book Series, Vol. 7). Dordrecht: Springer.

Han, S. (2009). Competence: Commodification of human ability. In K. Illeris (Ed.), International perspectives on competence development. London: Routledge.

Illeris, K. (2009). Competence, learning and education: How can competences be learned, and how can they be developed in formal education? In K. Illeris (Ed.), International perspectives on competence development. London: Routledge.

Lafer, G. (2004). What is 'skill'? Training for discipline in the low-wage labour market. In C. Warhurst, I. Grugulis, \& E. Keep (Eds.), The skills that matter. London: Palgrave Macmillan.

Lakoff, G., \& Johnson, M. (1980). Metaphors we live by. Chicago, IL: University of Chicago Press.

Livingstone, D. W., \& Guile, D. (Eds.). (2012). The knowledge economy and lifelong learning: A critical reader. Rotterdam, The Netherlands: Sense Publishers.

Mezirow, J. (2009). Transformative learning theory. In J. Mezirow \& E. Taylor (Eds.), Transformative learning in practice. San Francisco, CA: Jossey-Brass.

Morin, E. (1995). Introduction à la pensèe complexe. Paris: Seuil.

OECD. (2011). Education at a glance: OECD indicators. Paris: OECD Publishing.

OECD. (2012). Transferable skills training for researchers. Supporting career development and research. Paris: OECD Publishing.

OECD. (2013). Skills outlook 2013: First results from the survey of adult skills. Retrieved from http://dx.doi.org/10.1787/9789264204256-en

OECD. (2016). Education at a glance: OECD indicators. Paris: OECD Publishing.

Olesen, H. S. (2013). Beyond the current political economy of competence development. European Journal for Research on the Education and Learning of Adults, 4(2), 153-170.

Olsen, M., Codd, J., \& O’Neill, A. M. (2004). Education policy: Globalisation, citizenship and democracy. London: Sage Publications.

Rodriguez, D., Patel, R., Bright, A., Gregory, D., \& Gowing, M. K. (2002). Developing competency models to promote integrated human resource practices. Human Resource Management, 41(3), 309-324.

Sandberg, J. (2000). Understanding human competence at work: An interpretative approach. Academy of Management Journal, 43(1), 9-25.

Sawchuk, P. H. (2008). Labour perspectives on the new politics of skill and competency formation: International reflections. Asia Pacific Education Review, 9(1), 1-15. 
Scott, J. C. (2006). The Mission of the university: Medieval to postmodern transformations. The Journal of Higher Education, 77(1), 1-39.

Van der Weijden, I., Teelken, C., Drost, M., \& De Boer, M. (2015). Career satisfaction of postdoctoral researchers in relation to their expectations for the future. Higher Education, 72, 25-40.

Vieira, J. (2005). Skill mismatches and job satisfaction. Economics Letters, 89(1), 39-47.

VITAE. (2009). What do researchers do? First destinations of doctoral graduates by subject. Cambridge: The Careers Research and Advisory Centre (CRAC).

VITAE. (2010). What do researchers do? Doctoral graduate destinations and impact three years on. Cambridge: The Careers Research and Advisory Centre (CRAC).

Warhurst, C., Grugulis, I., \& Keep, E. (2004). The skills that matter. London: Palgrave Macmillan.

\section{Andrea Galimberti}

Bicocca University

Milan, Italy

Eva Ratti

C2t Consortium

Italy 